The Journal of Engineering and Exact Sciences - jCEC, Vol. 06 N. 05 (2020)

journal homepage: https://periodicos.ufv.br/ojs/jcec

doi: 10.18540/jcecvl6iss5pp0594-0606

OPEN ACCESS - ISSN: 2527-1075

\title{
VULCANIZAÇÃO COM PRODUTOS NATURAIS: UMA ANÁLISE ATRAVÉS DA MODELAGEM MOLECULAR
}

\section{VULCANIZATION WITH NATURAL PRODUCTS: AN ANALYSIS THROUGH OF MOLECULAR MODELING}

H. M. da $\operatorname{COSTA}^{1, *}$, V. D. RAMOS ${ }^{2}$

${ }^{1}$ Instituto Politécnico (IPRJ), Universidade do Estado do Rio de Janeiro (UERJ), Nova Friburgo - RJ/Brasil

${ }^{2}$ Universidade Estácio de Sá (UNESA), Nova Friburgo - RJ/Brasil

"Corresponding author. IPRJ / UERJ, Departamento de Materiais, Nova Friburgo, RJ, Brasil. Cep: 28.625-570. Phone: +55 2225332263

e-mail: hmcosta@iprj.uerj.br (H.M.da Costa).

\begin{tabular}{l} 
A R T I C L E I N F O \\
\hline Article history: \\
Received 2020-10-06 \\
Accepted 2020-12-12 \\
Available online 2020-12-12 \\
pal a vras - ch h v e \\
Modelagem molecular \\
Vulcanização \\
Óleos vegetais \\
$k$ e y wor $d s$ \\
Molecular modeling \\
Vulcanization \\
Vegetable oils
\end{tabular}

A B S T R A C T

In this investigation, experimental data of natural rubber (NR) and styrene-butadiene copolymer (SBR) rubber vulcanization with vegetable oils, peanut, coconut and linseed, in addition to beeswax, were validated through the molecular modeling of the main reactions of the process. Semi-empirical method AM1 (Austin Model 1) showed that the reduction in hardness, associated with solubility in the elastomeric matrix, is the factor that allows unsaturated fatty acids of 12 or more carbon atoms to act as activators in association with zinc oxide. However, steric impediment makes lignoceric acid, present in beeswax, a low performance activator. For the 18-carbon unsaturated fatty acids present in peanut and linseed oils, unsaturation increases the reactivity of the species generated during vulcanization. However, such a change in nature has an adverse effect, because probably induces side reactions that compromise the activating role of oils.

R E S U M O

Nesta investigação, os dados experimentais para a vulcanização da borracha natural (NR) $e$ do copolímero de estireno-butadieno (SBR) com óleos vegetais de amendoim, coco e linhaça, além da cera de abelha, foram validados através da modelagem molecular das principais reações do processo. O método semiempirico AM1 (Austin Model 1) permitiu comprovar que a redução da dureza, associada à solubilidade na matriz elastomérica, é o fator que permite que ácidos graxos insaturados de 12 ou mais átomos de carbono ajam como ativadores em associação com o óxido de zinco. Porém, o impedimento estérico torna o ácido lignocérico, presente na cera de abelha, um ativador de baixo desempenho. Para os ácidos graxos insaturados de 18 carbonos, presentes nos óleos de amendoim e linhaça, as insaturações aumentam a reatividade das espécies geradas na vulcanização. No entanto, tal alteração de natureza produz efeito adverso, pois provavelmente induz reações laterais que comprometem o papel ativador dos óleos. 


\section{INTRODUÇÃO}

A vulcanização de elastômeros ou borrachas pode ser compreendida como um processo de reticulação (formação de ligações cruzadas), onde as macromoléculas individuais presentes no polímero são convertidas em uma rede tridimensional elástica. Em geral, a vulcanização é conduzida através de uma composição que contém agentes de vulcanização (enxofre, óxidos metálicos, compostos bifuncionais ou peróxidos) e, se necessário, aceleradores, ativadores, cargas, retardadores etc. A composição é selecionada para produzir as características desejadas de vulcanização e, desta forma, propriedades de interesse nos vulcanizados são alcançadas módulo, resistência à tração, resistência à abrasão, entre outras (YANG et al., 2018).

Borrachas com utilização mais comum como, por exemplo, a borracha natural (NR) e o copolímero de estirenobutadieno (SBR), são vulcanizadas através de sistemas onde aceleradores orgânicos e ativadores estão sempre presentes. Os aceleradores são usados para reduzir o tempo do processo da vulcanização na reação do enxofre com os elastômeros; ao passo que, os ativadores são facilitadores da ação dos aceleradores, permitindo maior quantidade de ligações cruzadas. Os ativadores podem ser orgânicos ou inorgânicos, sendo o óxido de zinco $(\mathrm{ZnO})$ o ativador mais utilizado. A combinação de ácido esteárico (ativador orgânico) e óxido de zinco (ativador inorgânico) atualmente é a mais empregada no sistema de ativação (SABOYA, 2014; YANG et al., 2018).

Há algum tempo, nosso grupo de pesquisa tem buscado substituir o ácido esteárico nas composições usuais de NR e SBR por produtos naturais. Diferentes óleos vegetais (óleo de linhaça, óleo de coco e óleo de amendoim), além da cera de abelha (um subproduto da atividade apícola), foram testados e os diversos resultados - parâmetros da vulcanização e cinética, além da análise térmica dos ingredientes da composição e suas interações - foram reportados nos trabalhos de Bezerra et al. (2013 $a$ e $b$ ), Saboya (2014), Campbell (2016) e da Costa et al. (2017 $a$ e $b$ ).

Em linhas gerais, os experimentos demonstraram que os óleos vegetais apresentam um papel ativador nas composições elastoméricas, embora com uma ordem de eficiência diferenciada na formação de ligações cruzadas dada por: óleo de amendoim $\cong$ óleo de linhaça < óleo de coco. A cera de abelha em função da sua composição química bastante complexa e por não se encontrar purificada, pois foi empregada in natura, não foi considerada um ativador efetivo (BEZERRA et al., $2013 a$ e $b$; SABOYA, 2014; da COSTA et al., $2017 a$ e $b$ ).

Nas últimas décadas, a química molecular ou a modelagem molecular (MM) surgiu como faceta poderosa que proporcionou um melhor entendimento a nível molecular dos mecanismos de ação das moléculas - movimento molecular, transições de fase, mudanças conformacionais, fenômenos termodinâmicos etc. No entanto, um estudo nesse nível exige necessariamente três etapas: (i) a escolha de um modelo que represente com melhor aproximação as interações intra e intermoleculares de um sistema; (ii) a realização de cálculos quânticos; e, (iii) a interpretação dos resultados obtidos, validando ou rejeitando o modelo obtido. Essas etapas consideram três variáveis muito importantes: o tamanho do sistema a ser estudado (em termo do número de átomos), a precisão que se deseja nos resultados e o custo operacional (condições de hardware e software para a realização dos cálculos) (RIBEIRO, 2011).

Os três principais métodos teóricos para cálculos computacionais de propriedades moleculares podem ser classificados em: métodos empíricos (mecânica molecular); métodos semiempíricos (SE); e, cálculos ab initio (SCOTTI, 2006; ALBUQUERQUE, 2008).

A mecânica molecular consiste no uso das leis da física clássica e de resultados empíricos para modelagem da estrutura molecular e de propriedades químicas. Portanto, os cálculos de mecânica molecular incorporam apenas de modo indireto as informações eletrônicas dos sistemas químicos, trazendo grandes limitações no alcance teórico de seus resultados (SCOTTI, 2006; ALBUQUERQUE, 2008; LEAL et al., 2010; RIBEIRO, 2011).

Em contrapartida, os métodos semiempíricos são cálculos de orbital molecular (OM), empregando vários graus de aproximação e que usam apenas os elétrons de valência. De modo simplificado, pode-se dizer que os métodos mecânicoquânticos semiempíricos representam uma abordagem à solução das equações de Schrödinger para sistemas com muitos corpos (átomos, moléculas ou sólidos) usando a simulação numérica e computacional. A qualidade dos métodos semiempíricos depende das aproximações teóricas que lhe deram origem e da amplitude e qualidade da informação usada em sua parametrização (SCOTTI, 2006; ALBUQUERQUE, 2008; LEAL et al., 2010; RIBEIRO, 2011).

Por sua vez, os cálculos ab initio são cálculos mecânicoquânticos que usam equações exatas, sem aproximações, que envolvem a população eletrônica total da molécula. Os métodos são baseados no uso da equação de Schrödinger completa para tratar todos os elétrons de um sistema químico. Os métodos $a b$ initio trazem uma limitação computacional grande, pois o aumento no sistema eletrônico (quantidade de átomos na molécula ou número atômico dos átomos) produz um grande aumento no tempo computacional de cálculo, devido à grande quantidade de integrais que precisam ser resolvidas numericamente. Isto torna este poderoso método limitado para aplicação em sistemas moleculares maiores (enzimas, catalisadores etc.) (SCOTTI, 2006; ALBUQUERQUE, 2008; LEAL et al., 2010).

Uma vez que a modelagem molecular (MM) permite não apenas estimar as propriedades específicas de um composto, mas também auxilia na interpretação de reações químicas, o objetivo desse novo manuscrito é utilizar os recursos computacionais exigidos pela MM para a melhor compreensão teórica e validação dos dados experimentais obtidos nos trabalhos citados de Bezerra et al. (2013 $a$ e $b$ ), Saboya (2014), Campbell (2016) e da Costa et al. (2017 $a$ e $b$ ). Consideramos que a abordagem é inovadora, pois não encontramos um paralelo na literatura. Além disso, o óleo de coco mostrou-se um promissor substituto do ácido esteárico na vulcanização e a MM pode não apenas corroborar tal afirmação, mas também abrir perspectivas para a escolha de outros produtos de origem vegetal úteis ao processo.

Assim sendo, os principais constituintes da composição química dos óleos vegetais e da cera de abelha (ácidos graxos saturados com seis a vinte e quatro átomos de carbono na cadeia; e, ácidos graxos insaturados com dezoito carbonos na cadeia) foram selecionados como reagentes. Duas reações químicas 
envolvidas na vulcanização foram escolhidas e a modelagem através de um método semiempírico (SE) foi conduzida. O princípio de Pearson foi empregado para a interpretação dos resultados teóricos e um comparativo foi traçado com os resultados dos experimentos realizados por Bezerra et al. (2013 $a$ e $b$ ), Saboya (2014), Campbell (2016) e da Costa et al. (2017 $a$ e $b)$.

\section{METODOLOGIA}

\subsection{Produtos naturais e análise da vulcanização}

O processamento das diferentes composições de NR e SBR com os óleos vegetais e a cera de abelha, assim como os parâmetros característicos da vulcanização (tempo ótimo de cura, t $_{90}$; torques máximo e mínimo, $\mathrm{S}_{{ }_{\mathrm{h}}}$ e $\mathrm{S}{ }_{1}$, respectivamente; $\mathrm{e}$, tempo de pré-cura, $\mathrm{t}_{\mathrm{s} 1}$ ) foram devidamente descritos nos trabalhos de Saboya (2014) e da Costa $(2017, a)$. De igual maneira, a caracterização físico-química dos diferentes óleos vegetais e da cera de abelha é pormenorizada em Bezerra et al. (2013, $a$ e $b$ ) e Campbell (2016). Na Tabela 1 encontra-se a composição química aproximada dos óleos vegetais com os constituintes principais listados.

Tabela 1 - Composição química dos óleos vegetais (BEZERRA et al., $2013 a$ e $b$; CAMPBELL, 2016)

\begin{tabular}{llr} 
Produto Natural & Ácidos graxos & Porcentagem (\%) \\
Óleo de amendoim & Ácido palmítico & $6-16$ \\
& Ácido esteárico & $1,3-6,5$ \\
& Ácido oleico & $35-72$ \\
& Ácido linoleico & $13-45$ \\
& Ácido linolênico & $<0,3$ \\
Óleo de coco & Ácido láurico & \\
& Ácido mirístico & $40-50$ \\
& Ácido palmítico & $15-20$ \\
& Ácido esteárico & $9-12$ \\
& Ácido oleico & $2-4$ \\
& & $6-9$ \\
Óleo de linhaça & Ácido palmítico & $4-7$ \\
& Ácido esteárico & $2-4$ \\
& Ácido oleico & $14-30$ \\
& Ácido linoleico & $14-25$ \\
& Ácido linolênico & $45-60$ \\
\hline
\end{tabular}

É importante ressaltar que os principais constituintes dos óleos vegetais são os triacilgliceróis ou triglicerídeos. Os triacilgliceróis podem ser simples, nos quais todos os três grupos acila são os mesmos; ou, mais comumente, mistos onde os grupos acila são diferentes. A hidrólise de uma gordura (triacilgliceróis sólidos à temperatura ambiente) ou óleo (triacilgliceróis líquidos à temperatura ambiente) produz uma mistura de ácidos graxos. Os ácidos graxos contabilizam $95 \%$ da massa total dos triacilgliceróis e seu conteúdo é característico de cada óleo (SABOYA, 2014).

Por sua vez, a composição da cera de abelha depende em parte das subespécies de Apis mellifera, da idade da cera e das condições climáticas da sua produção. Esta variação ocorre principalmente na quantidade relativa dos diferentes componentes presentes do que propriamente na sua natureza. A mistura inclui hidrocarbonetos, ácidos graxos livres, monoésteres, diésteres, triésteres, hidroximonoésteres, hidroxipoliésteres, monoésteres de ácidos graxos, poliésteres de ácidos graxos e alguns componentes não identificados (CAMPBELL, 2016).

Desta maneira, a modelagem molecular foi conduzida baseando-se:

i) Nos ácidos graxos presentes na composição química dos óleos vegetais de amendoim, coco e linhaça; e, na cera de abelha. Um conjunto de ácidos graxos saturados de 6 a 24 átomos de $\mathrm{C}$ na cadeia foi selecionado, assim como ácidos graxos insaturados de 18 átomos de $\mathrm{C}$ na cadeia.

ii) $\mathrm{Na}$ escolha de reações químicas específicas presentes nos mecanismos cinéticos da vulcanização por benzosulfenamidas. Tais mecanismos são descritos por Coran (1964, $a, b$ e $c$; 1965) e Chapman (1978), conforme ilustram as reações (1) e (2) de Coran e as reações (3) a (5) de Chapmam.

$A \stackrel{k_{1}}{\rightarrow} B \stackrel{k_{2}}{\rightarrow} B^{*} \stackrel{k_{3}}{\rightarrow} \alpha V u$

$A+B^{*} \stackrel{k_{4}}{\rightarrow} \beta B$

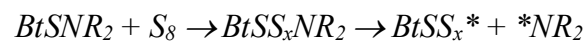

BtSS $_{x} *+$ Borracha $\rightarrow$ BtSS - Borracha

2 BtSS - Borracha $\rightarrow$ Borracha $-S_{x} S_{x}-$ Borracha +2 Bt $S^{*}$

No esquema reacional de Coran: A é o acelerador e/ou seus produtos de reação (com enxofre, $\mathrm{Zn}^{2+}$, etc.); B é o precursor de ligações cruzadas, provavelmente de natureza polimérica na forma de polissulfeto; $\mathbf{B}$ * é a forma ativa de $\mathbf{B}$, provavelmente um radical livre na forma de radical tiil ${ }^{*} ; \mathbf{V u}$ é a ligação cruzada formada; $\boldsymbol{\alpha}$ e $\boldsymbol{\beta}$ são ajustes estequiométricos. A borracha não é usada no esquema reacional de Coran, pois é considerada como estando em excesso, com uma concentração que permanece essencialmente constante durante o processo. Por sua vez, no esquema reacional de Chapman: Bt corresponde ao grupamento benzotiazol; enquanto, $\mathrm{BtSNR}_{2}$ é a molécula do acelerador.

As reações químicas (6) e (7), definidas a partir dos mecanismos descritos, foram consideradas fundamentais na formação de ligações cruzadas e foram selecionadas para a modelagem mocular.

$2 \mathrm{RCOOH}+\mathrm{ZnO} \rightleftharpoons \mathrm{Zn}(\mathrm{RCOO})_{2}+2 \mathrm{H}_{2} \mathrm{O}$

$\mathrm{Zn}(\mathrm{RCOO})_{2}+\mathrm{BtSS} S_{x} \rightleftharpoons$ Complexo sulfurante

A reação (6) foi interpretada como uma reação de metátese ou "reação de duplo deslocamento". O deslocamento da base $\mathrm{RCOO}^{-}$pela base $\mathrm{O}^{2-}$ é acompanhada pela extração de $\mathrm{H}^{+}$pelo ácido $\mathrm{Zn}^{2+}$. A reação (6) corresponde a reação entre o

*Tiil ou tiol, é um composto organossulfurado que contém um grupo $\mathrm{SH}$. 
ácido graxo (coativador) e o óxido de zinco (ativador), o que disponibilizaria no meio reacional, em uma forma solúvel, o cátion $\mathrm{Zn}^{2+}$. $\mathrm{O}$ carboxilato de zinco formado em (6) teria, então, a habilidade de reagir com polissulfetos $\left(\mathrm{BtSS}_{\mathrm{x}} \mathrm{Y}\right.$, produto originado de fragmentos do acelerador orgânico combinados com moléculas de enxofre, $\mathrm{S}_{8}$ ) e formar o complexo sulfurante na reação (7).

Guzmán et al. (2012) afirmam que no curso geral da vulcanização é geralmente aceito, mas ainda não de consenso comum, a natureza das espécies sulfurantes ativas e o mecanismo de sua reação com as macromoléculas de borracha, particularmente se o óxido de zinco é ou não envolvido. Diversos mecanismos têm sido propostos, mas a plena elucidação do mecanismo é ainda difícil por causa da complexidade e da dificuldade de análise dos vulcanizados.

Contudo, Ikeda et al. (2015) parecem ter chegado a uma resposta para tal problema utilizando in situ as espectroscopias de infravermelho e estrutura fina de absorção de raios $X$ (XAFS). Os autores investigaram a estrutura dos intermediários gerados a partir da reação entre o óxido de zinco e o ácido esteárico durante a vulcanização da borracha de isopreno. A estrutura dominante é a de um complexo bidentado de zinco/estearato em ponte com razão molar e número de coordenação inesperados de 1:1 e 4, respectivamente.

Tal complexo pode ser visualizado na Figura 1a. Os aceleradores usados nos manuscritos de Bezerra et al. (2013 $a$ e b), Saboya (2014), Campbell (2016) e da Costa et al. (2017 a e b) foram o N-ciclohexil-2-benzotiazol-sulfenamida (CBS) e o N-terc-butil-2-benzotiazol-sulfenamida (TBBS). As estruturas dos aceleradores são encontradas na Figura $1 b$.

(a)

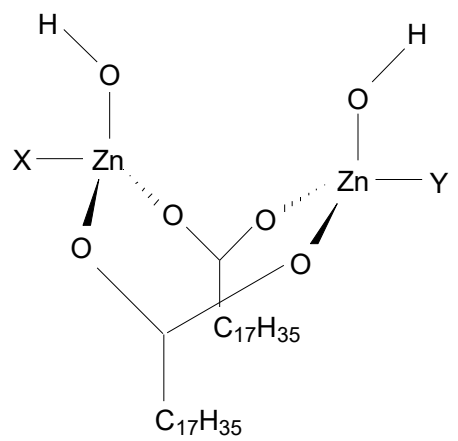

$\mathrm{X}$ e $\mathrm{Y}=\mathrm{H}_{2} \mathrm{O}$ e/ou um segmento de borracha

(b)

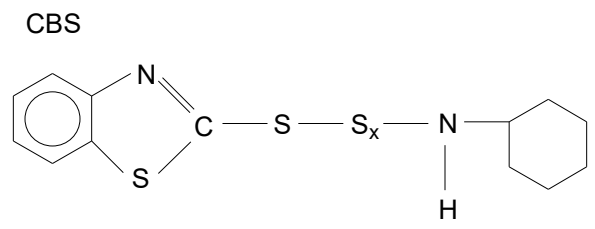

TBBS

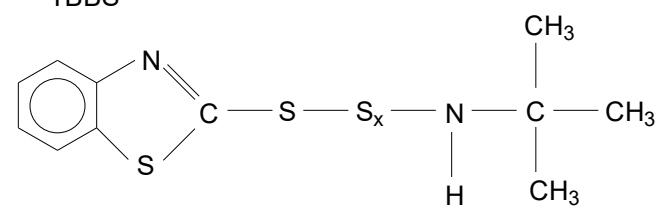

Figura 1 - (a) Estrutura do complexo zinco/estearato proposta por Ikeda et al. (2015); (b) Estrutura dos aceleradores orgânicos CBS e TBBS utilizados.

\subsection{Procedimento para modelagem molecular}

O processo de modelagem molecular foi conduzido através do programa HyperChem 7.0. Os métodos semiempíricos (SE) foram escolhidos em função da complexidade dos sistemas investigados e por permitirem maior velocidade nos cálculos dos parâmetros de interesse. $\mathrm{O}$ método AM1 (Austin Model 1) foi selecionado, pois é um dos mais usados entre todos os métodos semiempíricos para moléculas orgânicas (HYPERCHEM 7.0, 2002; SCOTTI, 2006; ALBUQUERQUE, 2008).

A rotina experimental adotada neste manuscrito envolveu primeiramente o cálculo da geometria molecular otimizada, ou seja, da estrutura tridimensional da molécula que apresentava a menor energia potencial. Tal etapa é primordial para que as demais propriedades moleculares de interesse possam ser estimadas como, por exemplo, o momento de dipolo elétrico $(\varepsilon)$; a área superficial (A) e o volume molecular (V); a energia (E) dos orbitais de fronteira (HOMO - orbital molecular ocupado mais alto, e LUMO - orbital molecular não ocupado mais baixo); o mapa de potencial eletrostático (MPE); e, o calor de formação $\left(\Delta \mathrm{H}_{\mathrm{f}}\right)$. Além disso, várias outras propriedades importantes podem ser estimadas, conforme as Equações abaixo (THANIKAIVELAN et al., 2000):

$$
\begin{aligned}
& \text { Índice de dureza }(\eta): \eta=\frac{1}{2} \cdot\left(E_{\text {lumo }}-E_{\text {homo }}\right) \\
& \text { Potencial químico }(\mu): \mu=\frac{1}{2} \cdot\left(E_{\text {lumo }}+E_{\text {homo }}\right) \\
& \text { Índice de maciez }(\mathrm{S}): S=\frac{1}{\eta} \\
& \text { Índice de eletronegatividade }(\chi): \chi=-\mu \\
& \text { Índice de eletrofilicidade }(\omega): \omega=\frac{\mu^{2}}{2 \eta}
\end{aligned}
$$

As condições gerais de modelagem adotadas foram: o método semiempírico AM1; o algoritmo de otimização de Polak-Ribiere (gradiente conjugado) para a minimização de energia com as opções de critério de convergência do gradiente RMS de 0,01 kcal.mol ${ }^{-1}$ ou um máximo de 1000 ciclos de interações; e, a molécula disposta no vácuo.

\section{RESULTADOS E DISCUSSÃO}

\subsection{Análise do efeito dos ácidos graxos saturados}

Nos trabalhos de Bezerra et al. (2013 $a$ e $b$ ) e Saboya (2014) foi verificado que as composições químicas dos óleos vegetais de amendoim, coco e linhaça são bastante variadas, embora sejam predominantemente ricas em determinados tipos de ácidos graxos. De igual maneira, a cera de abelha, embora possua complexa composição química, contém de $12 \%$ a $15 \%$ em ácidos graxos, onde é majoritária a presença do ácido lignocérico.

Uma vez que nos trabalhos supracitados ficou demonstrada uma relação direta entre a composição química dos produtos naturais e a vulcanização da borracha natural (NR) e do copolímero de estireno e butadieno (SBR), inicialmente escolhemos para a modelagem molecular uma ampla faixa de ácidos carboxílicos saturados, todos presentes em maior ou menor quantidade nos produtos naturais empregados - ver Tabela 2. 
Tabela 2 - Ácidos graxos saturados selecionados para os estudos das reações (6) e (7)

\begin{tabular}{ccl|}
$\begin{array}{c}\text { Número de } \\
\text { átomos de } \mathbf{C}\end{array}$ & Ácido & Estrutura \\
\hline $\mathbf{6}$ & Caproico & $\mathrm{H}_{3} \mathrm{C}\left(\mathrm{CH}_{2}\right)_{4} \mathrm{COOH}$ \\
$\mathbf{8}$ & Caprílico & $\mathrm{H}_{3} \mathrm{C}\left(\mathrm{CH}_{2}\right)_{6} \mathrm{COOH}$ \\
$\mathbf{1 0}$ & Cáprico & $\mathrm{H}_{3} \mathrm{C}\left(\mathrm{CH}_{2}\right)_{8} \mathrm{COOH}$ \\
$\mathbf{1 2}$ & Láurico & $\mathrm{H}_{3} \mathrm{C}\left(\mathrm{CH}_{2}\right)_{10} \mathrm{COOH}$ \\
$\mathbf{1 4}$ & Mirístico & $\mathrm{H}_{3} \mathrm{C}\left(\mathrm{CH}_{2}\right)_{12} \mathrm{COOH}$ \\
$\mathbf{1 6}$ & Palmítico & $\mathrm{H}_{3} \mathrm{C}\left(\mathrm{CH}_{2}\right)_{14} \mathrm{COOH}$ \\
$\mathbf{1 8}$ & Esteárico & $\mathrm{H}_{3} \mathrm{C}\left(\mathrm{CH}_{2}\right)_{16} \mathrm{COOH}$ \\
$\mathbf{2 0}$ & Araquídico & $\mathrm{H}_{3} \mathrm{C}\left(\mathrm{CH}_{2}\right)_{18} \mathrm{COOH}$ \\
$\mathbf{2 2}$ & Behênico & $\mathrm{H}_{3} \mathrm{C}\left(\mathrm{CH}_{2}\right)_{20} \mathrm{COOH}$ \\
$\mathbf{2 4}$ & Lignocérico & $\mathrm{H}_{3} \mathrm{C}\left(\mathrm{CH}_{2}\right)_{22} \mathrm{COOH}$ \\
\hline
\end{tabular}

Uma vez que temos ácidos carboxílicos cujas cadeias carbônicas variam de 6 até 24 átomos, a primeira questão a ser considerada é: Qual o comprimento ideal da cadeia carbônica do ácido carboxílico capaz de proporcionar uma ação ativadora efetiva na vulcanização?

De acordo com a literatura, a combinação do óxido de zinco $(\mathrm{ZnO})$ com um ácido graxo (ácidos carboxílicos alifáticos, tais como o ácido esteárico, o ácido palmítico ou ácido láurico) ou a utilização de sais de zinco destes ácidos tem um grande efeito no desenvolvimento da reação de vulcanização, aumentando a sua cinética. $\mathrm{O}$ efeito do ácido graxo aumenta com o número de átomos de carbono na sua cadeia carbônica. Particularmente, as características hidrofóbicas e hidrofílicas da molécula de ácido esteárico conferem-lhe uma maior solubilidade nas borrachas e conferem-lhe uma maior eficácia na ativação da vulcanização (CTB, 2020).

Carey (2011) considera o comportamento de solubilidade dos sais de ácidos carboxílicos que têm de 12 a 18 carbonos incomum. Os grupos carboxilato são hidrofílicos ("gostam de água") e tendem a conferir solubilidade em água às espécies que os contêm. As cadeias longas de hidrocarboneto são lipofilicas ("gostam de gordura") e tendem a associar-se a outras cadeias de hidrocarboneto. Quando o estearato de sódio é colocado na água, o grupo carboxilato hidrofílico favorece a formação de uma solução; a cadeia alquila lipofílica não favorece isso. A conciliação alcançada é a formação de uma dispersão coloidal de agregados chamados de micelas. As micelas formam-se espontaneamente quando a concentração de carboxilato excede determinado valor mínimo chamado de concentração micelar crítica. Cada micela é composta por 50 a 100 moléculas individuais, com os grupos carboxilato polares voltados para o exterior, onde experimentam forças de atração com a água e os íons sódio. As cadeias de hidrocarboneto apolares são orientadas para o interior da micela, onde forças dipolo induzido-dipolo induzido individualmente fracas, mas cumulativamente significativas, as mantêm juntas. As micelas são aproximadamente esféricas, porque uma esfera apresenta a superfície mínima para determinado volume de material e causa a menor desorganização à estrutura da água.

Assim, pelo exposto nos parágrafos anteriores, uma resposta preliminar seria que há necessidade de uma combinação satisfatória entre a solubilidade na matriz elastomérica e reatividade. Tal premissa parece ser encontrada somente quando a cadeia carbônica possui 12 ou mais átomos de $\mathrm{C}$, ou seja, ácidos graxos do ácido láurico em diante. A fim de corroborar com tal conclusão, as moléculas dos diferentes ácidos graxos foram modeladas e na Figura 2 encontram-se condensadas as informações obtidas. É observado que há uma relação linear entre o aumento gradativo da cadeia carbônica e o aumento verificado na área, volume e polarizabilidade da molécula. Por sua vez, a eletrofilicidade apresenta valores decrescentes com o aumento da massa molar dos ácidos graxos, embora uma correlação linear não possa ser sugerida.

Na Figura 2 também podem ser visualizados os índices de dureza e maciez dos ácidos graxos. Os índices foram estimados a partir do cálculo dos valores de energia para os orbitais moleculares HOMO e LUMO, ou seja, a energia dos orbitais de fronteira. Os elétrons do HOMO são de maior energia (e menos estabilizados) na molécula. Estes são geralmente os mais energeticamente acessíveis para reações com orbitais não ocupados de outros reagentes. Os orbitais HOMO podem doar elétrons; e, os orbitais LUMO podem aceitar elétrons nas reações (MIESSLER et. al., 2014). Através da Figura 2, é constatado que o aumento da cadeia carbônica dos ácidos graxos produz uma diminuição do índice de dureza $(\eta)$ ou, em outras palavras, ácidos graxos de maior massa molar apresentam moléculas com maior índice de maciez (S).

Segundo Pearson: "Os ácidos duros preferem ligar-se a bases duras e os ácidos moles preferem ligar-se a bases moles." As interações entre duas espécies moles ou duas duras são mais fortes do que aquelas entre uma espécie dura e uma mole (princípio HSAB). Tal estabilização é adicional a outros fatores que contribuem para a força de ligações entre doador e receptor. Esses fatores incluem o tamanho do cátion e do átomo doador; suas cargas; suas eletronegatividades; a sobreposição orbital entre eles; e, a formação do complexo com a substituição do ligante. Uma perspectiva simplista considera as interações duroduro como principalmente eletrostáticas (com uma alta contribuição iônica), com o LUMO do ácido muito acima do HOMO da base e mudança relativamente pequena nas energias dos orbitais na formação do aduto. Por sua vez, uma interação mole-mole envolve energias HOMO e LUMO que são muito mais próximas e provoca uma grande mudança nas energias dos orbitais durante a formação do aduto (HOUSECROFT e SHARPE, 2013; MIESSLER et. al., 2014).

A fim de que o princípio HSAB pudesse ser aplicado na interpretação do equilíbrio químico da reação (6), as espécies químicas $\mathrm{ZnO}, \mathrm{H}_{2} \mathrm{O}$ e os diferentes carboxilatos de zinco foram também modeladas. A estrutura idealizada para o óxido de zinco é vista na Figura 3 e os cálculos dos índices de dureza e maciez indicaram $\eta=5,01 \mathrm{eV}$ e $\mathrm{S}=0,20 \mathrm{eV}^{-1}$, respectivamente. Os índices encontrados para os diferentes carboxilatos de zinco são representados na Figura 4. Para a água, os valores encontrados foram $\eta=8,44 \mathrm{eV}$ e S $=0,12 \mathrm{eV}^{-1}$.

Assim sendo, encontramos no princípio HSAB argumentos qualitativos que corroboram as impressões iniciais sobre os ácidos graxos que podem ser efetivos na vulcanização. No sentido direto do equilíbrio químico da reação (6), o ácido graxo reagente deve apresentar uma dureza o mais próxima possível do óxido de zinco. Pelo gráfico da Figura 2, observa-se que somente a partir do ácido láurico (12 átomos de C) é que o índice $\eta$ mostra-se inferior a 6,1. Em contrapartida, no sentido inverso do equilíbrio químico da reação (6), os carboxilatos de 

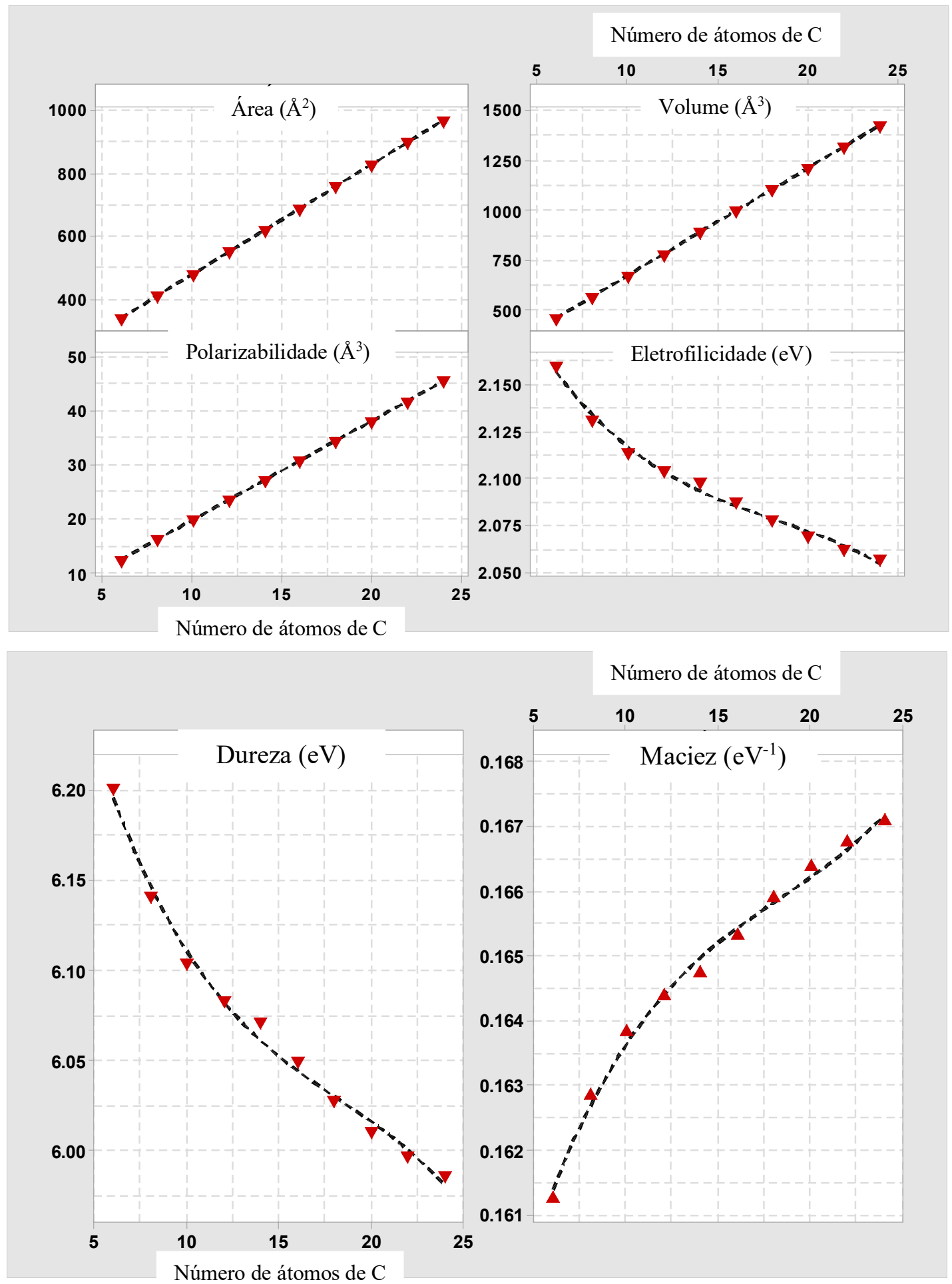

Figura 2 - Variações das propriedades das moléculas dos ácidos graxos (RCOOH), presentes nos óleos vegetais e cera de abelha, de acordo com o tamanho da cadeia carbônica. 


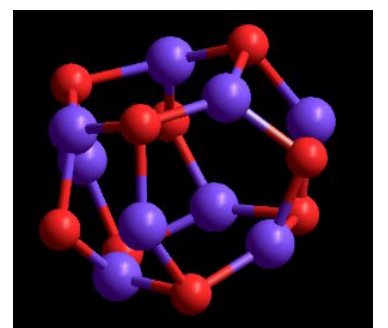

Figura 3 - Estrutura proposta para o $\mathrm{ZnO}$, um prisma hexagonal. Esferas em vermelho correspondem aos átomos de $\mathrm{O}$ e as esferas em roxo correspondem aos átomos de $\mathrm{Zn}$.

zinco devem apresentar dureza comparável com a água. Pelos cálculos efetuados, isso implica em um índice $\eta$ próximo a 8,44 eV. Na Figura 4 pode ser constatado que tal condição é mais apropriadamente obedecida quando os carboxilatos são formados a partir de ácidos graxos com um número de átomos de $\mathrm{C}$ igual ou abaixo de 10 átomos $(\eta>5,30 \mathrm{eV}$ e $\mathrm{S}<0,188 \mathrm{eV})$.

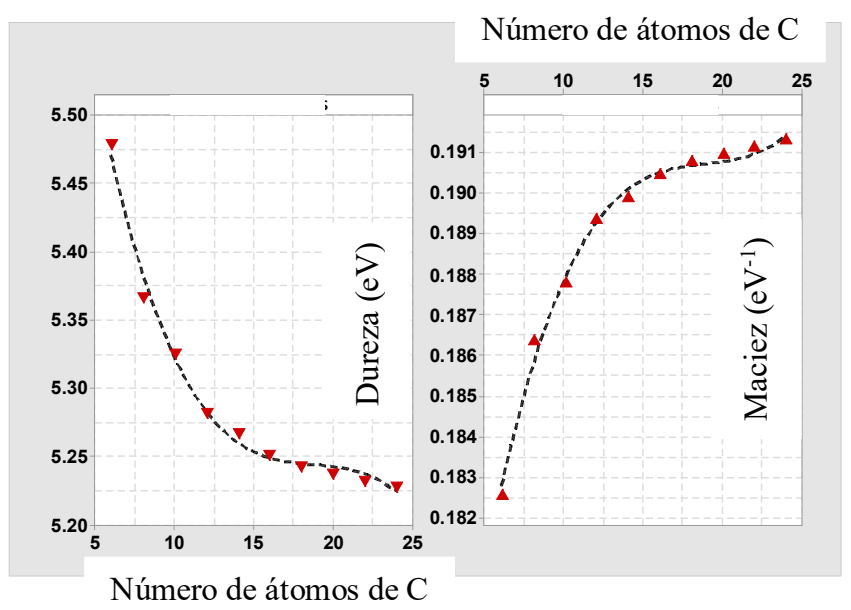

Figura 4 - Variação dos índices de dureza e maciez para os diferentes carboxilatos de zinco, $\mathrm{Zn}(\mathrm{RCOO})_{2}$.

Portanto parece ficar nítida, mais uma vez, a necessidade de os ácidos graxos possuírem cadeias carbônicas iguais ou superiores à doze átomos de $\mathrm{C}$. Uma condição que permite reatividade suficiente com o $\mathrm{ZnO}$ e uma constante de equilíbrio que tende a favorecer aos produtos. Em outras palavras, quando $\mathrm{C} \geq 12$ átomos a solubilidade na matriz elastomérica em conjunto com a reatividade são alcançados. Por sua vez, quando a cadeia carbônica possui 10 ou menos átomos de $\mathrm{C}$, a reação (6) tem baixa reatividade e o equilíbrio químico no sentido inverso é favorecido.

Estendendo a discussão do princípio HSAB para a reação (7), os carboxilatos de zinco gerados na reação (6) precisam ter reatividade para interagir com os polissulfetos orgânicos. Na Figura 5 são apresentados os valores de dureza para os diferentes polissulfetos que podem ser obtidos quando os aceleradores CBS ou TBBS são usados na vulcanização. Os aceleradores foram empregados nos trabalhos de Bezerra et al. (2013 $a$ e $b$ ), Saboya (2014) e Campbell (2016). Quando x =0, não há a formação do polissulfeto e a espécie química corresponde à própria molécula do acelerador.

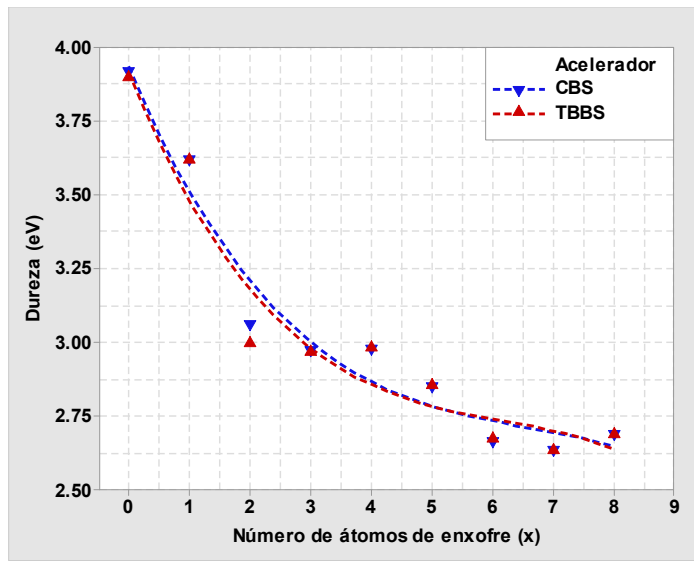

Figura 5 - Dureza dos polissulfetos $\mathrm{BtSS}_{\mathrm{x}} \mathrm{Y}$, formados a partir dos aceleradores orgânicos CBS e TBBS, de acordo com $o$ número $x$ de átomos de enxofre presentes.

Nos trabalhos investigados, um sistema de vulcanização convencional $(\mathrm{CV})$ foi escolhido, o que implica em uma relação quantitativa entre as concentrações de enxofre e acelerador superior a 1, ou seja, $\left[\mathrm{S}_{8}\right] /[$ Acelerador] $>1$. Em tal sistema, o elastômero possui ao final da vulcanização uma rede de ligações cruzadas com um percentual aproximado de $95 \%$ de ligações de natureza polissulfídica $(3 \leq \mathrm{x} \leq 6)$ e bissulfídica $(\mathrm{x}=2)$, o que proporciona elevada resistência à fadiga e resistência ao rasgo, por exemplo. Todavia, os vulcanizados irão dispor de baixa resistência à reversão e baixa resistência ao envelhecimento pelo calor (GHOSH et al., 2003).

Interpretando os dados da Figura 5 em conjunto com os da Figura 4, chega-se às seguintes conclusões:

- Os polissulfetos orgânicos, gerados a partir de fragmentos dos aceleradores CBS ou TBBS em combinação com o enxofre, são similares quanto à dureza para a faixa de valores de $\mathrm{x}$;

- As espécies polissulfídicas com $x \geq 6$ parecem atingir valores de dureza constantes na faixa de 2,66 a 2,68;

- A partir do laurato de zinco, $\mathrm{Zn}\left(\mathrm{H}_{3} \mathrm{C}\left(\mathrm{CH}_{3}\right)_{10} \mathrm{COO}\right)_{2}$, os carboxilatos seguintes (número de átomos de $\mathrm{C}>12$ ) apresentam índices $\eta$ progressivamente mais próximos àqueles que proporcionam reações efetivas com as espécies polissulfídicas.

Consequentemente, os resultados experimentais encontrados por Bezerra et al. (2013 $a$ e $b$ ), Saboya (2014), Campbell (2016) e da Costa et al. (2017 $a$ e $b$ ) podem agora ser embasados. Entre os óleos vegetais testados, as investigações apontaram o óleo de coco como o de melhor desempenho no papel de ativador, pois permitiu alcançar os maiores valores para o torque máximo $\left(\mathrm{S}_{\mathrm{h}}{ }_{\mathrm{h}}\right)$. Em outras palavras, ele produziu vulcanizados com maior número de ligações cruzadas polissulfídicas, ainda que o rendimento final tenha sido inferior ao da formulação tradicional com ácido esteárico. A razão sugerida para tal desempenho residiu na composição química rica em ácido láurico, cuja quantidade varia entre $44 \%$ e $52 \%$. Outros ácidos graxos saturados estão presentes, porém em quantidades menores: ácido caprílico, 5\% a 9\%; ácido cáprico, $6 \%$ a $10 \%$; ácido mirístico, $13 \%$ a $19 \%$; ácido palmítico, $8 \%$ a $11 \%$; ácido esteárico, $1 \%$ a $3 \%$; e outros em quantidades 
inferiores ou traços. Assim, o óleo de coco apresenta os requisitos, em termos de composição química, que o tornam útil como ativador.

Com relação aos outros óleos vegetais, o óleo de linhaça apresenta em sua composição química ácidos graxos saturados que variam de $6 \%$ a $11 \%$ e uma presença majoritária dos ácidos graxos insaturados - oleico (ômega 9), 13\% a 29\%; linoleico (ômega 6), 17\% a 30\%; e linolênico (ômega 3), 47\% a $55 \%$ - o que faz do óleo de linhaça um dos mais ricos em ácidos graxos essenciais. Ao mesmo tempo, o óleo de amendoim dispõe em sua composição química de uma concentração em torno de $36 \%$ a $67 \%$ em ácido oleico e 14\% a 43\% em ácido linoleico. Assim, a não ocorrência de ácidos graxos saturados em quantidades significativas é apontada como a causa da diminuição da eficiência dos óleos de linhaça e amendoim como ativadores. $\mathrm{O}$ efeito dos ácidos graxos insaturados será discutido na seção 3.2 .

Ainda que o princípio HSAB tenha ajudado a elucidar o porquê de o óleo de coco ser melhor como ativador do que os óleos de linhaça e amendoim, ainda há um questionamento que necessita de resposta. A cera de abelha possui $11 \%$ a $15 \%$ da composição química rica em ácidos graxos, onde se destaca a presença em ácido lignocérico. Por que a cera de abelha teve o pior desempenho como ativador entre os produtos naturais testados?

A explicação inicial de Bezerra et al. (2013 $a$ e $b$ ), Saboya (2014), Campbell (2016) e da Costa et al. (2017 $a$ e $b$ ) residiu na contaminação da cera de abelha por outras substâncias orgânicas diversas e a baixa concentração de ácidos graxos presentes $(12 \%$ a $15 \%)$ na composição química.

Buscando dar maior suporte à resposta para o baixo desempenho da cera de abelha, modelos tridimensionais dos complexos sulfurantes ativos foram propostos tomando-se por base a estrutura sugerida por Ikeda et al. (2015). Os modelos foram construídos a partir de fragmentos do acelerador CBS e dos ácidos láurico, esteárico e lignocérico. As estruturas dos complexos podem ser visualizadas na Figura 6.

A partir da Figura 6 observa-se que a geometria adotada pelos complexos para a minimização da repulsão entre os elétrons dos diferentes pares ligantes e não-ligantes é similar independente do ácido graxo considerado. Em todos os casos, as cadeias carbônicas são dispostas em lados opostos do plano central e o arranjo tridimensional permite, então, que os átomos de enxofre fiquem suficientemente "livres" para a interação com as cadeias elastoméricas.

Porém, os complexos sulfurantes devem se difundir entre as cadeias do elastômero para a formação das ligações cruzadas e, desta maneira, quanto maior o impedimento estérico encontrado, menor será a velocidade da reação de reticulação. Consequentemente, o complexo sulfurante a partir do ácido lignocérico deverá encontrar considerável dificuldade de se aproximar e interagir com as cadeias elastoméricas diante do seu tamanho. De acordo com os cálculos da modelagem molecular, o complexo do ácido lignocérico da Figura 6 apresenta um volume aproximado de $3976 \AA^{3}$ ao passo que o complexo do ácido esteárico é $16 \%$ menor com cerca de $3340 \AA^{3}$.

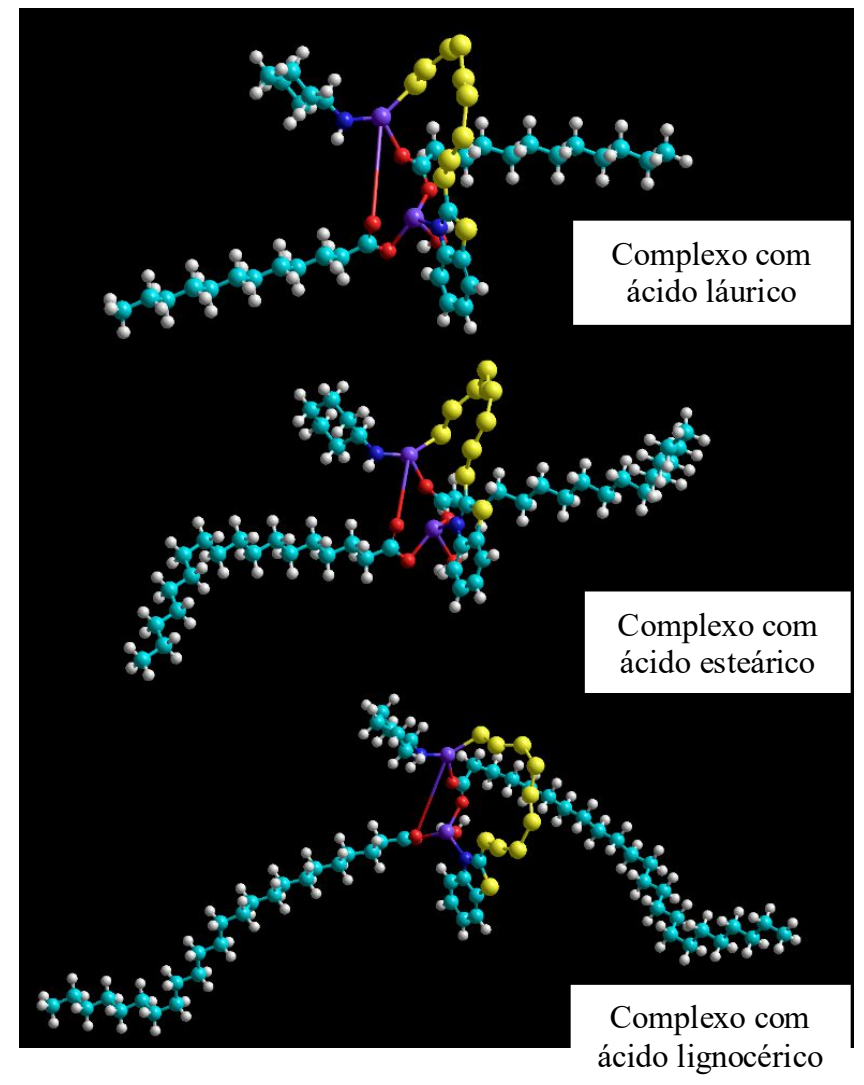

Figura 6 - Estruturas dos complexos ativos sulfurantes formados com oito átomos de enxofre e fragmentos do acelerador CBS e dos ácidos láurico, esteárico e lignocérico. Legenda: esferas azuis = átomos de $C$; esferas brancas $=$ átomos de $\mathrm{H}$; esferas vermelhas = átomos de $\mathrm{O}$; esferas amarelas $=$ átomos de $S$; e esferas violetas $=$ átomos de $Z n$

Os índices de dureza $(\eta)$ foram calculados para os complexos ativos sulfurantes formados com fragmentos de CBS e para àqueles gerados com fragmentos de TBBS. Na Figura 7, os valores de $\eta$ são apresentados. Os complexos sulfurantes com CBS não apresentaram variação significativa de $\eta$ com $o$ aumento da cadeia carbônica do ácido graxo. Um valor aproximadamente constante em torno de 2,50 foi encontrado. Portanto, o ponto chave parece não residir em reatividade ou equilíbrio químico, mas sim na cinética reacional. $\mathrm{O}$ impedimento estérico do complexo sulfurante do ácido lignocérico limita a interação com eficiência junto as cadeias elastoméricas e, desta maneira, não proporciona uma rede com ligações cruzadas em quantidades expressivas como àquelas geradas quando os ácidos láurico e esteárico estão presentes. Logo, além das impurezas e da baixa quantidade de ácidos graxos presentes na cera de abelha, o ácido majoritário da composição química, ácido lignocérico, não oferece uma velocidade reacional satisfatória para a vulcanização.

No que diz respeito aos complexos sulfurantes formados com fragmentos de TBBS, um aumento de natureza não linear foi encontrado nos valores de dureza com o aumento da cadeia carbônica do ácido graxo. Assim, o ácido lignocérico em sistemas de vulcanização com o acelerador TBBS é novamente desfavorecido. Do ponto vista cinético, o impedimento estérico não irá proporcionar uma velocidade satisfatória de reação de formação das ligações cruzadas entre as 
cadeias elastoméricas. Do ponto de vista da reatividade química, o aumento de dureza significa um aumento da diferença de energia entre os orbitais HOMO e LUMO dos complexos, o que pode representar um acréscimo de energia de ativação na reação com as cadeias de borracha.

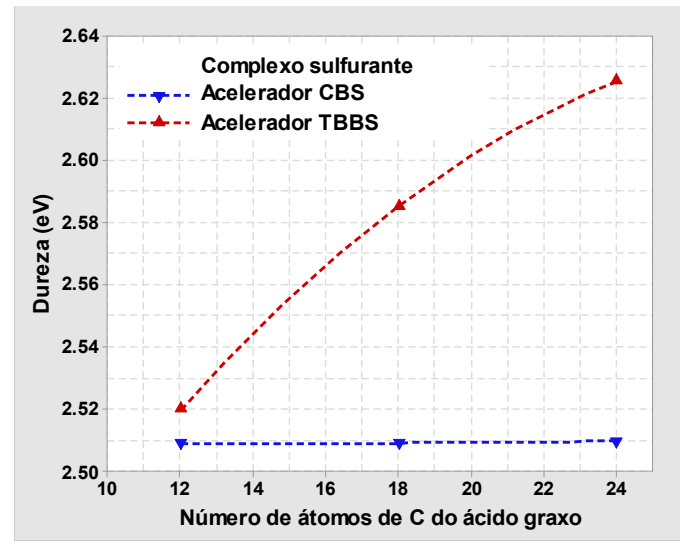

Figura 7 - Dureza dos complexos sulfurantes ativos formados a partir de oito átomos de enxofre, fragmentos do acelerador CBS ou TBBS e com o ácido graxo láurico, esteárico ou lignocérico.

Em da Costa et al. (2017 a) encontramos os resultados experimentais que suportam as hipóteses acima. Os dados do tempo de pré-cura $\left(t_{s 1}\right)$ e do tempo ótimo de cura $\left(t_{90}\right)$ em vulcanizados de $\mathrm{SBR}$ a $150^{\circ} \mathrm{C}$ foram superiores aos das demais composições contendo ácido esteárico ou óleos vegetais; enquanto, o torque máximo $\left(\mathrm{S}_{h}{ }_{h}\right)$, o que dá uma ideia da densidade de ligações cruzadas, só alcançou valor ligeiramente superior ao da composição com óleo de amendoim. Dessa forma, se em um primeiro momento o equilíbrio químico das reações (6) e (7) surge como favorável ao ácido lignocérico presente na cera de abelha, a velocidade reacional de reticulação acaba por não ser satisfatória em função da estrutura química do complexo sulfurante gerado.

Uma citação bibliográfica que reforça os argumentos discutidos é encontrada em Junkong et al. (2020), os quais estudaram o efeito de ácidos graxos com diferentes comprimentos de cadeia alifáticos durante a vulcanização da borracha de isopreno. Utilizando técnicas espectroscópicas in situ, os autores reportam que a estrutura do complexo sulfurante formado durante a vulcanização foi essencialmente o mesmo, independente do ácido graxo. Porém, a reatividade do ácido araquídico $\left(\mathrm{CH}_{3}\left(\mathrm{CH}_{2}\right)_{18} \mathrm{COOH}\right)$ foi considerada baixa sendo encontrado prolongados tempos de pré-cura e de cura, ou seja, uma lenta taxa reacional para a vulcanização. Ocorrência atribuída ao elevado impedimento estérico do complexo sulfurante no curso das reações de vulcanização.

\subsection{Análise do efeito dos ácidos graxos insaturados}

Os óleos vegetais de amendoim e linhaça apresentaram um desempenho, como ativadores do processo de vulcanização, inferior ao do óleo de coco, segundo os trabalhos de Bezerra et al. (2013 $a$ e $b$ ), Saboya (2014), Campbell (2016) e da Costa et al. (2017 $a$ e $b$ ). A composição química dos óleos de amendoim e linhaça apresenta um percentual majoritário de ácidos graxos insaturados com 18 carbonos - ácido oleico (ácido cis-9octadecenoico), ácido linoleico (ácido cis,cis-9,12octadecadienoico) e ácido linolênico (ácido cis, cis, cis-9,12,15octadecatrienoico). Assim, o questionamento é por que tais ácidos graxos insaturados se comportaram de maneira diferente do ácido esteárico (ácido octadecanoico)?

As moléculas dos ácidos graxos foram modeladas e alguns parâmetros de interesse são mostrados na Figura 8. Na Figura 9 são apresentadas as estruturas tridimensionais das moléculas com o respectivo mapa de potencial eletrostático (MPE).

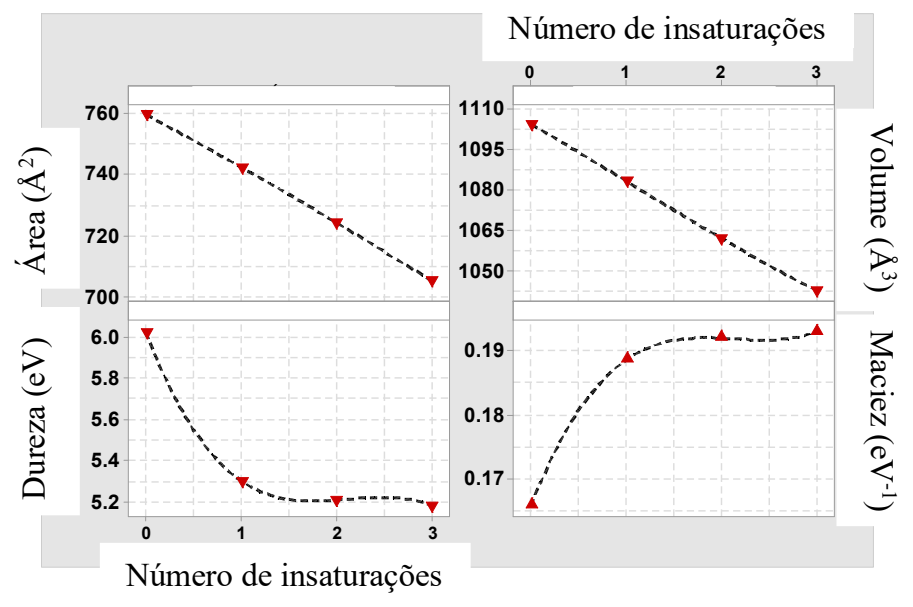

Figura 8 - Variação da área, volume, dureza e maciez dos ácidos graxos com 18 carbonos de acordo com o número de insaturações na cadeia.

Observa-se uma redução da área e do volume da molécula com o aumento do número de insaturações na cadeia carbônica. Tal comportamento é de natureza essencialmente linear e pode ser melhor entendido através da Figura 9. Uma ligação dupla é mais forte $(728 \mathrm{~kJ} / \mathrm{mol})$ e menor $(1,33 \AA)$ que uma ligação simples ( $377 \mathrm{~kJ} / \mathrm{mol}$ e $1,54 \AA$ ) $)$. Além disso, os dois orbitais $\mathrm{p}$ que se sobrepõem para formar a ligação $\pi$ precisam estar o mais paralelos possível um ao outro para a sobreposição ocorrer (SOLOMONS e FRYHLE, 2001). Isso significa que os átomos ficam no mesmo plano e os elétrons no orbital $p$ ocupam um volume do espaço acima e abaixo do plano. Portanto, a rotação livre da ligação dupla é impedida, enquanto a configuração cis adotada nos ácidos graxos insaturados gera o "dobramento" da molécula, o que explica a diminuição de área e volume.

A presença de insaturações diminuiu de forma acentuada a dureza $(\eta)$ ou, em outras palavras, aumentou consideravelmente a maciez $(\mathrm{S})$ dos ácidos graxos, conforme se verifica na Figura 8 . O valor de $\eta$ pareceu se estabilizar em torno de 5,2 quando o ácido linolênico foi alcançado. Em princípio, isto representa na reação (6) um reagente com maior reatividade em relação ao $\mathrm{ZnO}$ e, portanto, um deslocamento favorável ao equilíbrio químico no sentido dos produtos, ou seja, dos respectivos carboxilatos. As insaturações também provocaram uma mudança no perfil do MPE das moléculas, conforme ilustra a Figura 9. No ácido esteárico, as regiões negativas e positivas concentram-se na extremidade da molécula onde se encontra o grupamento $\mathrm{COOH}$, enquanto o restante da cadeia carbônica é essencialmente neutro. Em contrapartida, as insaturações geram novas áreas de acúmulo de carga negativa, o que pode ser 
verificado, indiretamente, pelo surgimento da coloração azul escura no MEP junto aos átomos de $\mathrm{H}$ distribuídos ao longo da

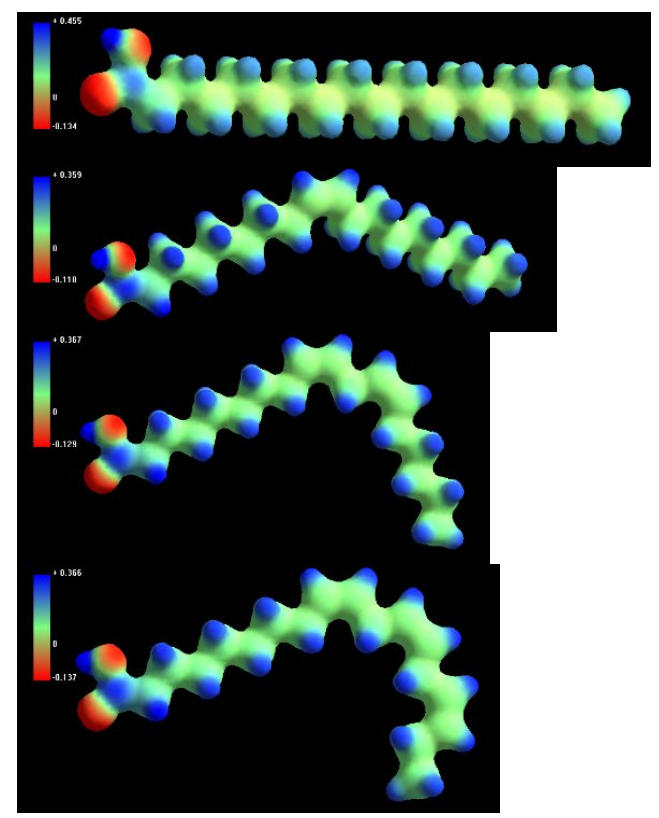

carbônica.

Figura 9 - Mapa de potencial eletrostático (MPE) das moléculas de ácido graxo com 18 átomos de carbono.

De cima para baixo: ácido esteárico, ácido oleico, ácido linoleico e ácido linolênico. Legenda: regiões mais positivas em azul e regiões mais negativas em vermelho.

Além da diminuição da dureza e aumento da reatividade dos ácidos graxos, a influência das insaturações presentes afetou a vulcanização dos elastômeros de outras maneiras. De acordo com Solomons e Fryhle (2001), os ácidos graxos insaturados não podem formar facilmente uma estrutura ordenada e, então, têm pontos de fusão menores do que os ácidos graxos saturados com o mesmo número de carbonos. Assim, os óleos de amendoim e linhaça são líquidos em temperatura ambiente, enquanto o ácido esteárico é sólido $\left(\mathrm{PF} \cong 70^{\circ} \mathrm{C}\right)$. O óleo de coco, em função do alto teor de ácido láurico e outros ácidos graxos insaturados, tende a se mostrar pastoso ou sólido em temperaturas inferiores a $25^{\circ} \mathrm{C}$. Em Saboya (2014) é apontado que o estado físico dos óleos facilitou a solubilização e a mistura dos ingredientes da composição, o que se refletiu em valores mais elevados de torque mínimo $\left(\mathrm{S}_{1}{ }_{1}\right)$ e menores valores do tempo de pré-cura $\left(t_{\mathrm{s} 1}\right)$, ou seja, o início da reação de vulcanização ocorreu com maior rapidez nas composições de NR com os óleos vegetais, particularmente o óleo de amendoim. Consequentemente, conciliando os dados experimentais de Saboya (2014) aos determinados mediante a modelagem molecular, é corroborada a hipótese da maior reatividade dos óleos vegetais insaturados como ativadores.

Prosseguindo a análise através da modelagem molecular, na Figura 10 são apresentados os dados de dureza e maciez dos carboxilatos de zinco gerados a partir de cadeias carbônicas com 18 átomos. Mais uma vez, o comportamento encontrando reforça as observações já feitas durante a análise da Figura 8. Os carboxilatos têm a dureza diminuída ou a maciez aumentada de forma acentuada com a introdução das insaturações, o que, pela Figura 5, implicaria em espécies de maior reatividade com os polissulfetos $\mathrm{BtSS}_{\mathrm{x}} \mathrm{Y}$. Portanto, a reação (7) seria mais favorecida na geração dos complexos sulfurantes quando os ólens de amendnim e linhaca fos Número de insaturações to

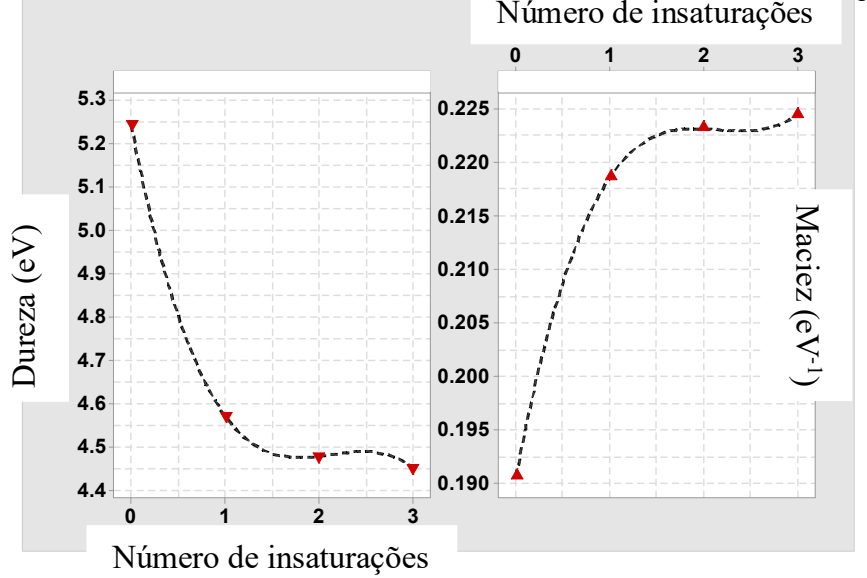

Figura 10 - $O$ efeito das insaturações sobre a dureza e a maciez dos carboxilatos de zinco gerados a partir de ácidos graxos com 18 carbonos.

Contrariamente ao esperado, em trabalhos de Bezerra et al. (2013 $a$ e $b$ ), Saboya (2014), Campbell (2016) e da Costa et al. (2017 $a$ e $b$ ), os experimentos demonstraram que os óleos de amendoim e linhaça tiveram um papel ativador nas composições elastoméricas, porém com uma eficiência de formação de ligações cruzadas inferior inclusive ao óleo de coco. Então, a questão final a ser abordada é: $\mathrm{O}$ que ocasiona o baixo desempenho desses óleos vegetais insaturados?

Um fator que explica o observado é a tendência que os compostos com ligações duplas $\mathrm{C}=\mathrm{C}$ têm de sofrerem reações de adição. Duas características da ligação dupla ajudam a compreender por que tais reações de adição ocorrem: (a) Uma reação de adição é o resultado da conversão de uma ligação $\pi \mathrm{e}$ uma ligação $\sigma$ em duas ligações $\sigma$. Normalmente, o resultado dessa troca é favorável energeticamente; (b) Os elétrons da ligação $\pi$ estão expostos. Como a ligação $\pi$ resulta da sobreposição de orbitais $\mathrm{p}$, os elétrons $\pi$ se localizam acima e abaixo do plano da ligação dupla. A ligação $\pi$ é particularmente suscetível a reagentes ávidos por elétrons (reagentes eletrofílicos - reagentes positivos como os prótons, reagentes neutros e os ácidos de Lewis) (SOLOMONS e FRYHLE, 2001). Logo, as insaturações permitem a maior reatividade dos ácidos graxos nas reações de vulcanização, mas propiciam todo uma gama de possíveis reações laterais. Por conseguinte, o balanço final é um ativador de menor desempenho.

Na Figura 11 são apresentados dos dados de dureza $(\eta)$ e maciez (S) dos complexos sulfurantes propostos por Ikeda et al. (2015) adaptados para os aceleradores CBS e TBBS e os ácidos graxos de 18 carbonos. O efeito das insaturações é novamente determinante na redução da dureza dos complexos, particularmente, quando se observa os complexos gerados a partir de fragmentos do acelerador TBBS - um decréscimo já pronunciado de $\eta$ com a inclusão de apenas uma insaturação na cadeia carbônica é claramente visível. Mais uma vez, a questão recai sobre uma reatividade acentuada dos complexos sulfurantes com a presença de diferentes sítios para ataques eletrofílicos, o que, consequentemente, permite reações laterais 
e diminui a eficiência na formação de ligações cruzadas entre as cadeias elastoméricas.

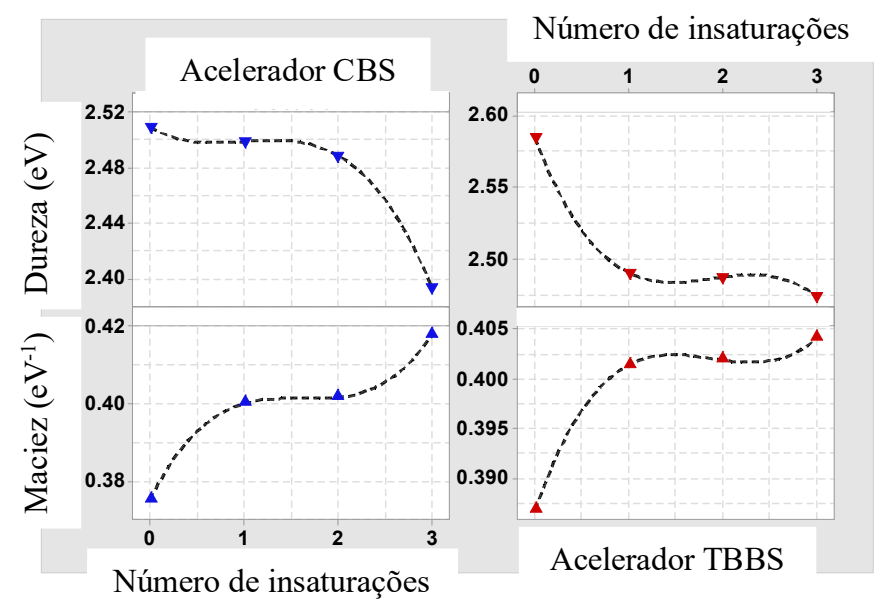

Figura 11 - Efeito das insaturações sobre a dureza e a maciez dos complexos sulfurantes ativos formados a partir de oito átomos de enxofre, fragmentos do acelerador CBS ou TBBS e os ácidos graxos com 18 carbonos.

Em Saboya (2014), por exemplo, encontramos respaldo para tais considerações. A borracha natural vulcanizada pelo sistema convencional em $160^{\circ} \mathrm{C}$ apresentou tempo ótimo de cura ( t $_{90}$ ) entre 9 e 10 minutos, enquanto o torque máximo alcançado $\left(\mathrm{S}_{\mathrm{h}}{ }_{\mathrm{h}}\right)$ foi de aproximadamente $66 \mathrm{dN}$.m. Quando os óleos de linhaça e amendoim substituíram o ácido esteáricos, os valores de $t_{90}$ ficaram entre 6 e 7 minutos, porém $\mathrm{S}_{\mathrm{h}}$, foi reduzido para 57 dN.m e $58 \mathrm{dN} . \mathrm{m}$, respectivamente.

A Figura 12 corresponde ao mapa de potencial eletrostático (MPE) dos diferentes complexos sulfurantes formados com os ácidos graxos esteárico, oleico, linoleico ou linolênico, fragmentos do acelerador CBS e oito átomos de enxofre. É nítida pela codificação de cores como as insaturações mudam a distribuição de cargas ao longo do complexo. No complexo sulfurante formado pela molécula do ácido esteárico há uma faixa $+2,10$ (azul) até $-0,07$ (vermelho) para as regiões carregadas positiva e negativamente, respectivamente. As regiões em tons laranja e vermelho se distribuem por toda a estrutura do complexo, particularmente pela área onde se encontram os átomos de enxofre alinhados (extremo esquerdo).

Em contrapartida, no complexo sulfurante formado pela molécula do ácido linolênico, as três insaturações presentes na cadeia do ácido graxo não apenas "dobram" o complexo em um formato mais compacto, mas também concentram as regiões de carga negativa essencialmente no extremo direito, ou seja, sobre a cadeia carbônica. Além disso, há também um decréscimo na faixa de distribuição de cargas, a qual varia de $+0,72$ até $-0,01$. Outra vez, a modelagem molecular fornece os indícios que corroboram os dados experimentais e as suposições dos trabalhos de Bezerra et al. (2013 $a$ e $b$ ), Saboya (2014), Campbell (2016) e da Costa et al. (2017 $a$ e $b$ ).

Um argumento final para demonstrar a possibilidade de reações laterais em complexos sulfurantes ativos formados pelas moléculas dos ácidos graxos insaturados apoia-se no manuscrito de Pereira et al. (2016). Os autores do manuscrito descrevem que o HOMO ou o LUMO podem não ser parâmetros determinantes no curso de reações químicas, mas sim o próximo orbital ou qualquer orbital que tenha energia muito próxima do HOMO ou do LUMO, ou seja, é importante investigar o papel do orbital molecular de fronteira efetivo para a reação (FERMO). Assim, investigamos a disposição dos orbitais HOMO com energias próximas e na Figura 13 estes são apresentados para dois complexos sulfurantes ativos.

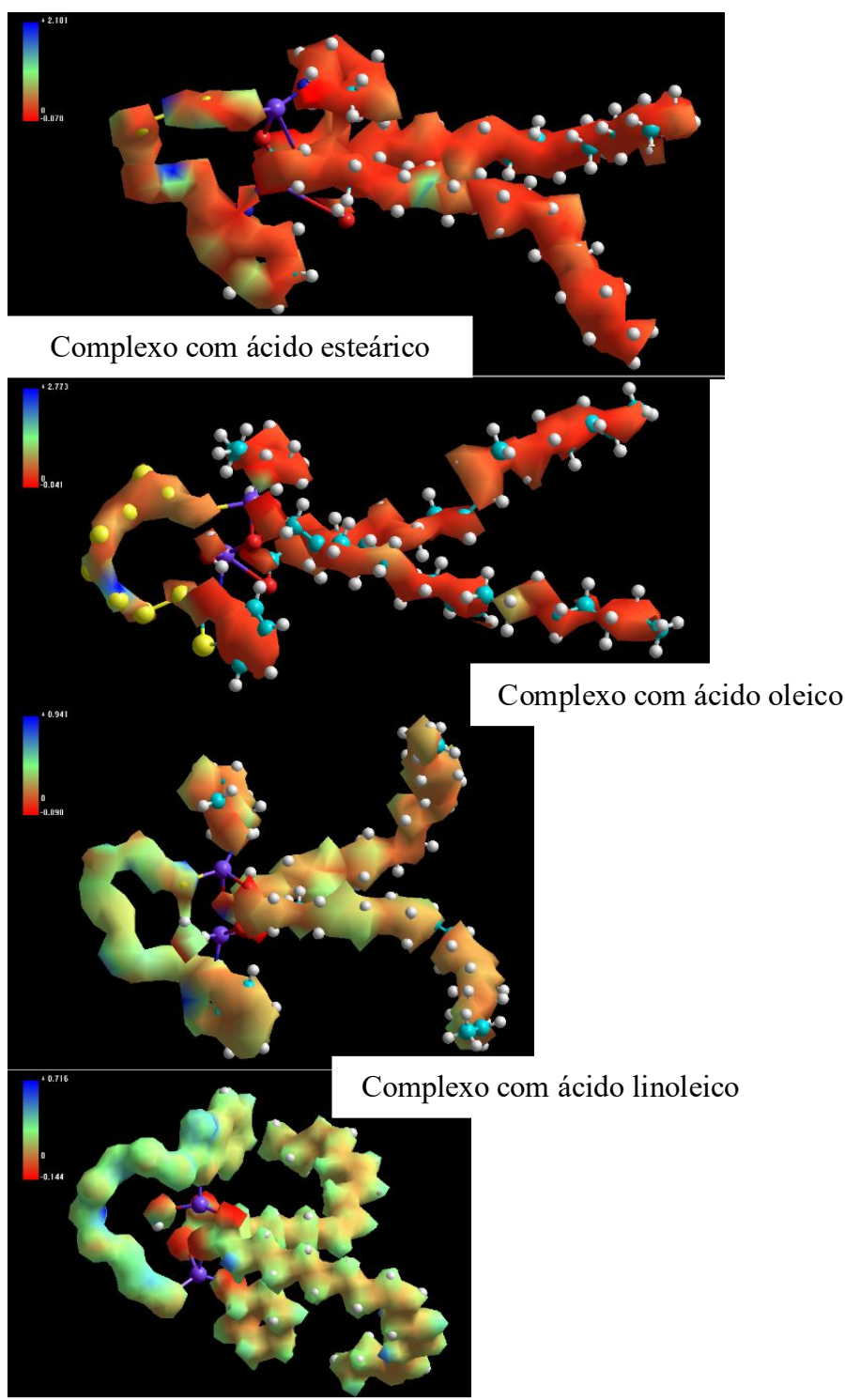

Complexo com ácido linolênico

Figura 12 - Mapa de potencial eletrostático (MPE) dos complexos sulfurantes ativos formados pelas moléculas de ácidos graxos com 18 carbonos, fragmentos do acelerador CBS e oito átomos de enxofre. Legenda: regiões mais positivas em azul e regiões mais negativas em vermelho.

Os orbitais HOMO 0 e HOMO +4 do complexo sulfurante ativo com ácido esteárico estão dispostos sobre os átomos de enxofre. Para o orbital HOMO 0, o valor de energia calculado foi de $-8.14 \mathrm{eV}$; enquanto para o orbital $\mathrm{HOMO}+4 \mathrm{a}$ energia foi de $-9.29 \mathrm{eV}$. Portanto, uma diferença de $1,15 \mathrm{eV}$. No complexo sufurante ativo do ácido linolênico, o orbital HOMO +4 é deslocado para as insaturações presentes na cadeia carbônica e as energias calculadas foram: HOMO 0, -7.99 eV; 
e, $\mathrm{HOMO}+4,-9.30 \mathrm{eV}$. Uma diferença energética de 1,31 eV. Assim, ainda que o incremento de energia para se alcançar o orbital de fronteira HOMO 0 seja maior, as ligações duplas $\mathrm{C}=\mathrm{C}$ proporcionam novos sítios reacionais e, consequentemente,

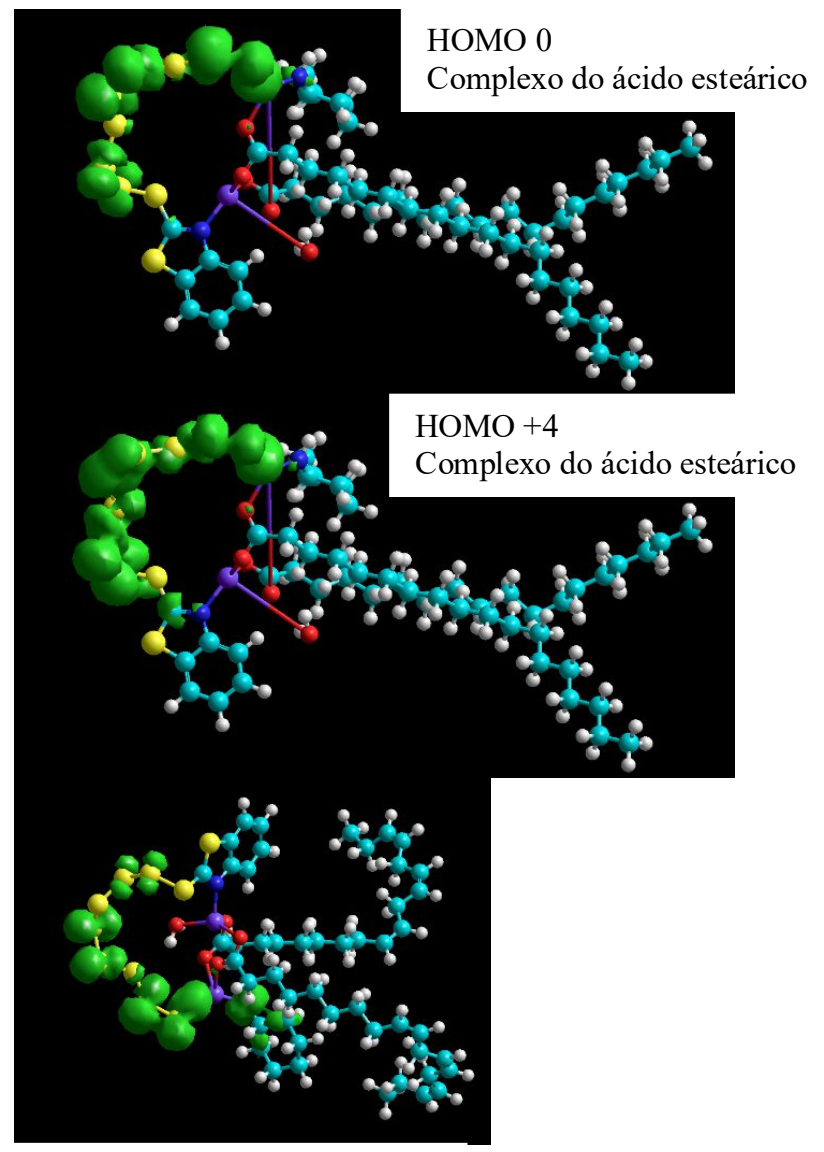

HOMO 0

Complexo do ácido linolênico

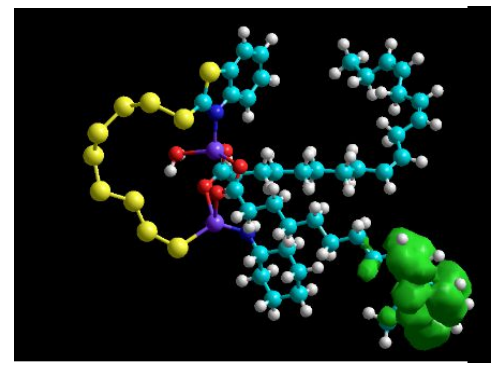

$\mathrm{HOMO}+4$

Complexo do ácido linolênico

oportunidades de ocorrência de reações laterais.

Figura 13 - Orbitais HOMO 0 e HOMO +4 representados para os complexos sulfurantes ativos gerados pelos

fragmentos do acelerador CBS, ácidos esteárico e linolênico e oito átomos de enxofre.

\section{CONCLUSÕES}

A modelagem molecular através do método semiempírico AM1 foi implementada para o estudo das principais reações que ocorrem durante a vulcanização dos elastômeros NR e SBR. Os dados teóricos alcançados permitiram validar as observações experimentais encontradas nos trabalhos de Bezerra et al. (2013 $a$ e b), Saboya (2014), Campbell (2016) e da Costa et al. (2017 $a$ e $b$ ).

\section{De um modo geral:}

I. Solubilidade na matriz elastomérica e aumento da reatividade ocasionada pela diminuição da dureza $(\eta)$ são os fatores que permitem que ácidos graxos insaturados com 12 carbonos ou mais sejam úteis na vulcanização. Porém, ácidos graxos com cadeias carbônicas excessivamente grandes como o ácido lignocérico (24 átomos de C) não são ativadores eficientes em função do impedimento estérico gerado nas espécies químicas derivadas. Tais observações explicam o desempenho satisfatório do óleo de coco e a baixa eficiência da cera de abelha, respectivamente.

II. Para ácidos graxos com 18 carbonos, a presença de insaturações permite uma diminuição da dureza das espécies, cuja magnitude depende do acelerador considerado no sistema de vulcanização - CBS ou TBBS. Porém, o ganho de reatividade das espécies, em particular, do complexo sulfurante formado pela reação (7), não se reflete em ganho efetivo de eficiência. As insaturações acabam por, provavelmente, permitir maior número de reações laterais indesejáveis, o que atenua a ação dos óleos de linhaça e amendoim, ricos em ácidos graxos insaturados, como ativadores.

III. A utilização de produtos naturais como óleos vegetais se mostra verdadeiramente útil, considerando a substituição do ácido esteárico, somente se o óleo escolhido apresentar em sua composição química teores majoritários de ácidos graxos saturados com cadeias entre 12 e 18 átomos de C. A mesma consideração pode ser tomada como válida para outros produtos de origem natural.

Agradecimentos: Os autores agradecem aos órgãos de fomento CAPES, CNPq e FAPERJ pelo suporte financeiro e ao Programa Pesquisa \& Produtividade 2020 da UNESA/RJ.

\section{REFERÊNCIAS}

ALBUQUERQUE, C. A. Modelagem molecular aplicada ao desenvolvimento de sistemas nanoscópicos bioativos. 2008. 133 f. Dissertação (Mestrado em Materiais para Engenharia) - Universidade Federal de Itajubá (UNIFEI), Itajubá, MG, 2008.

aBEZERRA, A.; SANTOS, A. C. S.; DA COSTA, H. M.; RAMOS, V. D. Efeito do óleo de linhaça e do óleo de amendoim sobre a vulcanização da borracha natural (NR). Parte I: Modelo Generalizado. Polímeros, v. 23, n. 3, p. 395-401, 2013.

bBEZERRA, A.; SANTOS, A. C. S.; DA COSTA, H. M.; RAMOS, V. D. Efeito do óleo de linhaça e do óleo de amendoim sobre a vulcanização da borracha natural (NR). 
Parte II: Modelo Detalhado. Polímeros, v. 23, n. 4, p. 493$500,2013$.

CAMPBELL, B. C. Análise térmica aplicada ao estudo das reações de vulcanização em elastômeros - efeito de óleos vegetais e da cera de abelha. 2016. 142 f. Dissertação (Mestrado em Ciência e Tecnologia de Materiais) Instituto Politécnico (IPRJ), Universidade do Estado do Rio de Janeiro (UERJ), Nova Friburgo, RJ, 2016.

CAREY, F. A. Química Orgânica. $7^{\text {st }}$ ed., Porto Alegre: ARTMED Editora S.A., v. 2, 2011.

CHAPMAN, D. A. Vulcanization of rubber. Model for efficient sulfenamide-sulfur systems. Journal of Elastomers and Plastics, v. 10 (April), p. 129, 1978.

${ }^{\mathrm{a} C O R A N}$, A. Y. Vulcanization. Part IV. The effects of compounding variables on the nature of rubber networks. Rubber Chemistry and Technology, v. 37, p. 673, 1964.

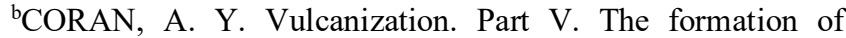
crosslinks in the system: natural rubber - sulfur - MBT zinc ion. Rubber Chemistry and Technology, v. 37, p. $679,1964$.

${ }^{\mathrm{c}}$ CORAN, A. Y. Vulcanization. Part VI. A model and treatment for scorch delay kinetics. Rubber Chemistry and Technology, v. 37, p.689, 1964.

CORAN, A. Y. Vulcanization. Part VII. Kinetics of sulfur vulcanization of natural rubber in presence of delayedaction accelerators. Rubber Chemistry and Technology, v. 38, p. 1, 1965.

CTB - Ciência e Tecnologia da Borracha. Endereço eletrônico: www.ctborracha.com. Consulta em julho de 2020.

aDA COSTA. H. M.; RAMOS, V. D.; SIRQUEIRA, A. S. Influência dos óleos vegetais e da cera de abelha sobre a vulcanização do copolímero de estireno-butadieno (SBR). The Journal of Engineering and Exact Sciences (JCEC), v. 03, n. 7, p. 955-974, 2017.

bDA COSTA, H. M.; RAMOS, V. D.; CAMPBELL, B. C.; DE ANDRADE, M. C. Thermal analysis of the sulfur vulcanization. Part III: The role of linseed oil and peanut oil as activators. Journal of Thermal Analysis and Calorimetry, v. 129, v. 2, p. 755-766, 2017.

GHOSH, P.; KATARE, S.; PATKAR, P.; CARUTHERS, J. M.; VENKATASUBRAMANIAN, V.; WALKER, K. A. Sulfur vulcanization of natural rubber for benzothiazole accelerated formulations: from reaction mechanisms to a rational kinetic model. Rubber Chemistry and Technology, v. 76, n. 3, p. 592, 2003.

GUZMÁN, M.; VEGA, B.; AGULLÓ, N.; BORRÓS, S. Zinc oxide versus magnesium oxide revisited. Part 2. Rubber Chemistry and Technology, v. 85, n. 1, p. 56-67, 2012.

HYPERCHEM $^{\circledR}$ Release 7 for Windows. Tools for Molecular Modeling. Hypercube Inc., January, 2002.

HOUSECROFT, C. E.; SHARPE, A. G. Ácidos, bases e íons em solução aquosa. In: Química Inorgânica. $4^{\text {st }}$ ed., Rio de Janeiro: LTC - Livros Técnicos e Científicos Editora Ltda., v.1, cap. 7, p. 187, 2013.

IKEDA, Y.; YASUDA, Y.; OHASHI, T.; YOKOHAMA, H.; MINODA, S.; KOBAYASHI, H.; HONMA, T. Dinuclear bridging bidentate zinc/stearate complex in sulfur cross-linking of rubber. Macromolecules, v. 48, n. 3, p. 462-475, 2015.

JUNKONG, P.; MORIMOTO, R.; MIYAJI, K.; TOHSAN, A.; SAKAKI, Y.; IKEDA, Y. Effect of fatty acids on the accelerated sulfur vulcanization of rubber by active zinc/carboxylate complexes. Royal Society of
Chemistry, v. 10, p. 4772-4785, 2020.

MIESSLER, G. L.; FISCHER, P. J.; TARR, D. A. Orbitais moleculares. In: Química Inorgânica, $5^{\text {st }}$ ed., São Paulo: Pearson Education do Brasil, cap. 5, p. 117, 2014.

PEREIRA, D. H.; LA PORTA, F. A.; SANTIAGO, R. T.; GARCIA, D. R.; RAMALHO, T. C. Novas perspectivas sobre o papel dos orbitais moleculares de fronteira no estudo da reatividade química: uma revisão. Revista Virtual da Química, v. 8, n. 2, p. 425-453, 2016.

RIBEIRO, L. Caracterização de estado sólido e análise computacional de uma nova forma cristalina do fármaco antifilariose dietilcarbamazina: um sal de ácido maleico. 2011. 119 f. Dissertação (Mestrado em Física) - Instituto de Física de São Carlos (IFSC), Universidade de São Paulo (USP), São Carlos, SP, 2011.

SABOYA, J. C. C. Efeitos dos óleos vegetais de linhaça e de amendoim sobre a vulcanização da borracha natural (NR). 2014. 61 f. Dissertação (Mestrado em Ciência e Tecnologia de Materiais) - Instituto Politécnico (IPRJ), Universidade do Estado do Rio de Janeiro (UERJ), Nova Friburgo, RJ, 2014.

SCOTTI, L. Modelagem molecular aplicada à cosmetologia: planejamento de compostos antienvelhecimento. 2006. 169 f. Doutorado (Programa de Pós-Graduação em Fármaco e Medicamentos) - Universidade de São Paulo (USP), São Paulo, SP, 2006.

SHRIVER, D. F.; ATKINS, P. W. Química Inorgânica. $3^{\text {st }}$ ed., Porto Alegre: ARTMED Editora S.A., 2003.

SOLOMONS, T. W. G.; FRYHLE, C. B. Química Orgânica. $7^{\text {st }}$ ed., Rio de Janeiro: LTC Editora, v. 1, 2001

THANIKAIVELAN, P.; SUBRAMANIAN, V.; RAO, J. R.; NAIR, B. U. Application of quantum chemical descriptor in quantitative structure activity and structure property relationship. Chemical Physics Letters, v. 323, n. 1-2, p. 59-70, 2000.

YANG, J. K.; PARK, W.; RYU, C.; KIM, S. J.; KIM, D.; SEO, G.; KIM, J. H.; CHUNG, C. B. Roles of sulfur and accelerators in the vulcanization of SBR compounds deduced through simulation. Rubber Chemistry and Technology, v. 91, n. 3, p. 595-608, 2018. 